\title{
SMOOTHIE OR FRUIT SALAD? LEARNERS' DESCRIPTIONS OF ACCENTS AS WINDOWS TO CONCEPT FORMATION
}

\section{ALICE HENDERSON}

Université de Savoie-Mont Blanc, France

alice.Henderson@univ-savoie.fr

\begin{abstract}
This paper explores the linguistically naive descriptions which one set of EFL learners provided when identifying and describing accents. First and second-year English majors at a French university were asked to do two tasks. First, they listened to two extracts to determine whether the speaker's accent sounded more British or American, and to explain which features helped them to decide. Later they answered two questions: a) What do you do when you want to sound more like an American? and b) more like a British person? The analysis of their answers highlights learners' underlying representations of accents as well as concept formation in relation to English pronunciation. I argue that this cognitive aspect of L2 learning should be addressed explicitly in instruction.
\end{abstract}

\section{Introduction}

Folk linguistics has a broad remit to explore "the nature and value of lay knowledge, beliefs and theories for the development of theoretical frameworks and practical solutions for everyday language problems" (Wilton \& Stegu, 2011, p. 1). Its research questions often overlap with those of the subfield perceptual dialectology (Preston, 1999; Preston, 2011). Both fields rely on the fact that people are sensitive to variation in accents and dialects (Boughton, 2006). However, when people put words to the thoughts they have about accents, they may "have few metalinguistic terms to describe the sounds of words" (Fraser, 2006, p. 67). According to Bloch and Trager (1942):

In popular speech, terms descriptive of speech sounds are almost exclusively auditory; they refer, in a vague way, to the hearer's impression. Thus, the vowel of cash is 'flat', the vowel of calm 'broad'; the g of get is 'hard', the g of gem 'soft'. (pp. 11-12)

When asked to describe varieties of English, learners can come up with surprising descriptions, i.e. the Os are deeper, it sounds more liquid, or sounds are waving at the back of your throat, creatively referring to "domains" such as music, texture, space, movement or even food: 
The British accent is like a fruit salad whereas an American accent is like a smoothie. They both contain fruits and they both taste really good, but they're still different. (2nd year student)

For the learner who made this comment, a smoothie might be referring to connected speech phenomena such as elision and coalescence and separate chunks of fruits could be referring to a non-tapped intervocalic / $t /$. However, the exact referent of the food and the truth value of the learner's analysis are not of interest here. This paper argues that such descriptions are potentially useful windows onto an individual's formation of phonological concepts. My assumption is that becoming aware of these, and making them explicit (see DeKeyser \& Juffs, 2005; Dörnyei, 2009), can help individuals to improve their pronunciation of a non-native language.

\section{Theoretical framework}

The theoretical framework for this study draws on the concepts of salience, metaphonological awareness, and socially constructed metalanguage, and assumes a process of concept formation. The difference between explicit and implicit learning must also be clarified, if any practical applications are to be drawn from the results

\subsection{Salience $($ salient $=$ notable, important, prominent, noticeable)}

The concept of salience has been discussed in various fields such as communication, semiotics, linguistics or psychology, to mention but a few. In terms of language learning, Ellis (2006) says that:

Out of all the available stimuli, the cues that affect our learning are the stimuli that the individual pays most attention to. [...] Our implicit models of the world induce a variety of perceptual biases, a range of phenomena of learned selective attention. (p. 165)

Given this assumption, language learners would arguably base their implicit models of what a language or accent should sound like upon what they find salient and pay attention to. Because people have different phonological concepts based on their language and literacy background (Strange, 1995; cited in Fraser, 2006, p. 71) and, because native phonological systems have been shown to influence speech perception (Hume \& Johnson, 2001), it would seem logical for language learners from different linguistic backgrounds to find different features salient.

When trying to predict what might be salient, I have chosen to use contrastive analyses, in this case of French and English but also of two varieties of English. Contrastive Analysis (CA) has serious shortcomings, most notably its inability to accurately predict positive or negative transfer between the mother tongue and an additional language (Rasier \& Hiligsmann, 2007). However, anecdotal evidence shows that when people are asked what makes learning a particular langauge difficult, they often point to what is different, such as the Spanish jota, the English "TH sounds", consonant clusters in Polish or tones in Chinese. Such features would seem prime 
candidates for saliency. According to Walter's (2001) CA description, French-speaking learners on the whole find links between spelling and pronunciation challenging, have difficulties with English word stress and unstressed syllables, and may find the following consonants difficult to perceive or pronounce, especially in consonant clusters: $/ \theta \partial \mathrm{t} d \mathrm{~d}$ $\mathrm{r} \mathrm{h} \mathrm{\eta} /$. All diphthongs and several vowels may be problematical, especially /I $\mathrm{D} \wedge$ $\mho$ ว/. Moreover, Walter states that the articulatory settings are different: "French uses tenser, more rounded lips and more frequent jaw opening; the tip of the tongue is not used, and there is more use of the blade" (ibid., p. 53). Honikman (1964) defines articulatory setting as:

[...] the overall arrangement and manoeuvring of the speech organs necessary for the facile accomplishment of natural utterance. Broadly, it is the fundamental groundwork which pervades and, to an extent, determines the phonetic character and specific timbre of a language. (p. 73)

She also provides a detailed comparison of articulatory settings for French and English, reproduced in Table 1:

\begin{tabular}{|l|l|l|}
\hline Jaws & \multicolumn{1}{|c|}{ English } & \multicolumn{1}{c|}{ French } \\
\hline Lips & Loosely closed (not clenched) & Slightly open \\
\hline State of oral cavity & Neutral; moderately active & $\begin{array}{l}\text { Rounded; vigourously active } \\
\text { in spreading \& rounding }\end{array}$ \\
\hline $\begin{array}{l}\text { Main consonant } \\
\text { articulation }\end{array}$ & Relaxed & Theeks contracted \\
\hline Tongue: & To roof laterally & Blade-dental \\
\hline Anchorage & Tapered & To floor centrally \\
\hline Tip & Slightly concave to roof & Untapered \\
\hline Body & Concave to roof & Neutral to roof \\
\hline Underside &
\end{tabular}

Table 1. Articulatory settings of (British) English and French (Honikman, 1964).

The French university students in the current study could be expected to notice some of these features, perhaps especially the more readily visible jaw and lip settings.

In terms of features which distinguish varieties of English such as General American English (GAE) and Standard Southern British English (SSBE), the phonemic differences are much greater for vowels (especially low back vowels) than for consonants (CelceMurcia, Brinton, Goodwin, \& Griner, 2010, pp. 450-451), with allophonic variations being greater than the inventories. Realisations of $/ \mathrm{t} /, / \mathrm{r} /$ and $/ 1 /$ can differ considerably and the glottal stop may also be distinctive:

The more frequent use of the glottal stop as well as glottalized stop consonants in final position gives British English its more clipped and precise quality. (ibid., p. 458)

The presence of consonant clusters and of reduced syllables is not generally distinctive, although schwas seem more widespread in GAE, where the distinction 
between weak /I/ and schwa is not as prevalent as in SSBE (Wells, 2008, p. 892). CelceMurcia, M., Brinton, D. M., Goodwin, J. M. and Griner, B. list 42 lexical items where word stress is distinctive (in addition to numerous place names), concluding that "there is more syllable reduction in multisyllabic words in British English and greater use of light stress in NAE along with a tendency to retain syllables" (2010, p. 457). In terms of voice quality, GAE is described as more nasal, the liquids $/ 1 /$ and $/ \mathrm{r} /$ as having a more velarized quality, and the jaw position as being slightly more open (p. 458). To conclude, when comparing these two accents, very phonetically-oriented French learners of English might be expected to comment on vowels (esp. low back ones), diphthongs, realisations of $/ \mathrm{t} /, / \mathrm{r} /, / 1 /$ and $/ \mathrm{P} /$, and perhaps voice quality, especially as jaw aperture is also different from their native French.

\subsection{Metaphonological awareness (MPA), socially constructed metalanguage (SCM), and concept formation}

Being able to label a certain accent as more or less rhotic constitutes an example of meta-phonological awareness (MPA), defined by Wrembel (2011) as

explicit knowledge of selected aspects of L2 phonetics and phonology, analytic awareness of the formal properties of the target language as contrasted with the learner's L1 as well as a considerable level of processing control. (p. 106)

Wrembel argues that metacognitive reinforcement plays an essential role in developing L2 pronunciation competence (2005), which concurs with Couper's findings (2011) in this respect. Couper tested the effect of socially constructed metalanguage (SCM), showing that the right kind of SCM helps learners to form new concepts, with significant positive effects on L2 production. Both MPA and SCM involve explicit naming and awareness of features and are seen as influencing the formation of concepts.

In cognitive psychology, concepts are important because they influence categorization processes. In this respect, Bruner, Goodnow and Austin (1967) distinguish concept formation from concept attainment:

the formation of the hypothesis that some mushrooms are edible and others are not is the act of forming a concept. Attainment refers to the process of finding predictive, defining attributes that distinguish exemplars from nonexemplars of the class one seeks to discriminate. (p. 22)

In relation to language, concept formation relies on Saussure's insight that the signified (meaning or content) is a concept: the word "tree" represents the entire category of trees (Saussure, 1916/2013). Fraser (2011) highlights a second key insight of Saussure's, that the signifier (a sound or form) is also a concept; to interpret a picture of a dog, a person needs two concepts: [dog] and [picture of a dog]. "Without that second concept, the picture is ... merely a random pattern of marks on a surface, with no connection to the concept [dog]" (p. 124).

Fraser then makes an analogy between drawing and pronunciation, in order to explain the formation of implicit concepts. In drawing and speaking, both the signifier 
and signified are concepts. Both are skills which involve representation and where the signifier is an act, involving physical as well as cognitive factors. Adults have difficulty learning to draw because of "entrenched concepts of what dogs ought to look like" (p. 127). In relation to pronunciation, a key factor impacting on what is pronounced is "entrenched concepts of what signifiers ought to sound like" (p. 128). In pronouncing the word "dog" the speaker is not just moving the vocal tract; they are doing that in order to create a series of sounds which express the meaning of the word "dog". Communication is possible because both speakers attribute the same meaning to the signifier and the signified.

It is a well-known fact that many people fail to achieve acceptable, easily intelligible pronunciation in a foreign language and this failure impacts on successful communication. In the same way, many people fail to learn to draw beautifully, so drawing must involve more than a set of lines and rules that govern the lines. One key aspect in improving this skill is learning to "see" reality differently, for example developing an "eye" for shapes and shadows as opposed to just lines; skill in physically handling a stick of chalk or a paintbrush develops concurrently. Similarly, pronunciation is both an articulatory and a cognitive process (ibid.). Extending Fraser's analogy, mastery of acceptable, flowing speech or conversation involves going beyond the articulatory mechanics of individual phonemes or even words. Developing an "eye" or an "ear" requires enhanced or qualitatively different awareness or noticing.

\subsection{Explicit and implicit learning}

This study tries to reveal what French students notice when they hear different accents of English. I argue that even though implicit concepts themselves are unobservable, if they can be expressed in or implied from words, they constitute a potentially useful entry point for learners, the place where they could start developing an eye or an "ear". This raises the question of explicit and implicit learning, or what Dörnyei calls "the core dilemma in instructed second language acquisition: the uneasy relationship" between the two (2009, p. 268). Dörnyei defines explicit teaching as "any consciously applied teaching practice that elicits explicit learning" (p. 269) and argues for the complementary use of explicit and implicit instruction. According to DeKeyser and Juffs, "the advantage of explicit over implicit instruction is the most clearly documented method effect in the empirical literature on types of instruction" (2005, p. 442; cited in Dörnyei, 2009, p. 272). In Dörnyei's description of five ways in which explicit learning mechanisms support implicit ones, the argument that "explicit knowledge fills the gaps of implicit knowledge" (p. 172) is perhaps the most appropriate for French university students. It is safe to assume that, after six to nine years of classroom instruction, such students possess a fair amount of implicit knowledge about English. However, pronunciation instruction can still have an impact ${ }^{1}$ on bad habits which learners may have developed.

Teachers have an important role to play here, even if they understand phonological theory or articulatory details to varying degrees (Kirkova-Naskova et al., 2013). They

\footnotetext{
${ }^{1}$ See Couper (2006) for an excellent review of research on this issue.
} 
may feel uncomfortable involving their students in the creation of metalanguage to describe how they perceive pronunciation phenomena or processes. However, cognitive aspects can and should be addressed in pronunciation instruction, because improving pronunciation requires "changing the concepts that drive it" (Fraser, 2006, p. 69). The adult brain has established ways of categorising sounds based on the first language acquired and these categories need modifying (Leather, 1999). As a first step to affecting such modifications in the pronunciation of a group of French-speaking learners of English - via changes in their instruction - this paper attempts to reveal salient features of two accents. The research question is: What types of features are salient enough for students to comment on them? As this study is primarily descriptive and given the issues raised in the literature review, the hypothesis is that first and second-year students will comment differently for each accent and for each task.

\section{Method}

\subsection{Participants}

Participants were English majors at a French university. A total of 120 students were contacted and slightly different numbers participated in Task $1(\mathrm{~N}=30+27)$ and in Task 2 $(\mathrm{N}=33+23)$, where the first number indicates the number of first-year students and the second number second-year students. Information about the age and gender of participants was not gathered. However, they were predominantly female and first-year students tend to be 18-20 years old. Students whose native language was not French were excluded. Second-year students had already had a year of explicit classroom instruction: 12 one-hour weekly pronunciation classes and accompanying one-hour language lab session, as well as 12 hours of lectures on the phonetics and phonology of English.

\subsection{Procedure}

Two sets of data were collected. To minimise the influence of previous and current teaching, Task 1 data was collected in the first 2-3 weeks of the university year, before explicit teaching on segmentals (in $1^{\text {st }}$ year) and at the start of a unit on syllable structure (in $2^{\text {nd }}$ year). Thirty first-year and 27 second-year students responded. In this task, students were asked to listen to two extracts via their electronic learning platform ${ }^{2}$. It was assigned as homework but they were told it was part of a research project and would not be marked. One extract was a female presenter from the BBC programme FastTrack (11 seconds) and the second was the American comedian Jerry Seinfeld (15 seconds) ${ }^{3}$.

\footnotetext{
${ }^{2}$ Wikipedia defines this as "a range of integrated web based applications that provide teachers, learners, parents and others involved in education with information, tools and resources to support and enhance educational delivery and management" (2015).

${ }^{3}$ See Appendix for the script of each.
} 
Students had to determine whether the speaker's accent was more British or American and explain which features helped them to decide this. They could listen at a time of their choosing over a two-week period. They typed their (anonymous) answers directly onto the learning platform and received no specific feedback about their answers.

This first prompt (in Task 1) elicited predominantly lists of technical terms (such as rhotic and tap/flap) and few evaluative comments, the latter being more desirable in this study because they potentially reveal more about underlying representations. Evaluative comments were defined as those with adjectives (i.e. cool, posh, deeper), adverbs (i.e. seriously, slowly), quantifiers (i.e. some, a bit), comparatives and superlatives (i.e. more, less, faster/slower) as well as connotative verbs and nouns (i.e. force, vomit). Therefore, a second set of data was collected two months later. In Task 2, students were asked to answer two questions by writing on a piece of paper: What do you do when you want to sound more like an American? more like a British person? Thirty-three first-year and 23 second-year students responded. The fact that some had responded in Task 1 was assumed not to induce bias in their Task 2 replies, as they had received no feedback on the initial task. Table 2 summarizes the characteristics of each data collection Task:

\begin{tabular}{|l|l|l|}
\hline \multicolumn{1}{|c|}{ Task 1 } & \multicolumn{1}{|c|}{ Task 2 } \\
\hline $\begin{array}{l}\text { Student } \\
\text { participants }\end{array}$ & $301^{\text {st }}$ years, 27 $2^{\text {nd }}$ years & 33 1st years, 23 $2^{\text {nd }}$ years \\
\hline Time \& timing & 2 weeks; early in semester & 2 weeks; 2 months later \\
\hline Medium & On-line & On paper \\
\hline $\begin{array}{l}\text { Requested } \\
\text { action }\end{array}$ & Identify and list & Explain how to/give advice \\
\hline Type of question & Closed & Open \\
\hline Nature of replies & Mostly descriptive & More evaluative \\
\hline Examples & $\begin{array}{l}\text { The way he pronounces } \\
\text { TOAST, MURDR } \\
\text { No flapping in CITIES or } \\
\text { TWENTY }\end{array}$ & $\begin{array}{l}\text { More pretentious } \\
\text { More raxed } \\
\text { Mouth only open a bit compared } \\
\text { to a British accent }\end{array}$ \\
\hline
\end{tabular}

Table 2. Characteristics of Task 1 and Task 2.

Initially the limits of the countable unit "a comment" were determined by spacing (written on separate lines or as bullet-points), capital letters or punctuation, with units separated by commas, full stops, colons or semi-colons. However, in certain cases the unit had to be semantically delimited. For example, the line use every letter in words, try to pronounce well has one comment unit, despite the comma. In contrast, the line seems more royal, more haughty // the sounds are quite distinct// the Os are "deeper" has three separate comment units, as materialised by //.

Students' comments were analysed to see which types of features they noticed (i.e. speech rate, rhoticity), the categories being derived from their responses. Linguistically inaccurate comments were not eliminated (i.e. she doesn't pronounce all the Rs so it's American, final $R$ is stressed, ex: engineeR). These two examples were classified as attempts to describe the pronunciation of $/ \mathrm{r} /$. Similarly, comments citing the word 
MURDER or an ambiguous comment such as I know it's American because of the way he says YEARS were interpreted as references to the realization of $/ \mathrm{r} /$.

The data were then analysed again to identify evaluative comments and these were re-organized into new, data-driven categories. I was the only person to categorize the data, first in November 2014, and then again in February 2015. Where differences were spotted in February, colleagues were asked to help categorize the comments.

\section{Results and Discussion}

This section presents the summary of the most frequently commented on features for Task 1 (Listen and identify the accent) and for Task 2 (What would you do to sound more ...), as well as the results for each task.

\subsection{Task 1: Identify}

Few students wrote symbols in their answers, instead writing, for example, the letter $T$ or $R$ when referring to phonemes like /t/ or / r/ respectively. Therefore, in the results, comments grouped together as referring to $/ \mathrm{r} /$ cover a variety of comments, for example: say more $R s$, roll Rs, final $R$ is replaced by a schwa, it's not rhotic, or pronounce / $r /$ only when a vowel follows. Similarly, the lexical set GOAT (Wells, 1982) is used to regroup their answers, even though none of them referred to "GOAT"; participants provided an example word (i.e. toast), wrote the $O A$ sound or a few second-year students used symbols /əv/ or /ov/.

Table 3 presents a summary of the six features most frequently commented on in Task 1 , in decreasing order by frequency of occurrence:

\begin{tabular}{|l|c|l|c|}
\hline \multicolumn{2}{|c|}{ American extract } & \multicolumn{2}{c|}{ British extract } \\
\hline $\begin{array}{c}\text { Features commented } \\
\text { on ... }\end{array}$ & $\begin{array}{c}\text { Total } \mathbf{n}^{\circ} \text { of } \\
\text { comments } \\
(\mathbf{n = 5 7 )}\end{array}$ & $\begin{array}{c}\text { Features commented } \\
\text { on ... }\end{array}$ & $\begin{array}{c}\text { Total } \mathbf{n}^{\circ} \text { of } \\
\text { comments } \\
(\mathbf{n}=\mathbf{5 7})\end{array}$ \\
\hline Vowels & 20 & $/ \mathrm{t} /$ & 34 \\
\hline /t/ & 19 & $/ \mathrm{r} /$ & 20 \\
\hline GOAT & 18 & Vowels & 11 \\
\hline /r/ & 16 & $\begin{array}{l}\text { Intonation; Stressed } \\
\text { words }\end{array}$ & 6 \\
\hline Enunciation & 7 & Speech rate & 3 \\
\hline Speech rate; Intonation & 6 & Diphthongs & 2 \\
\hline
\end{tabular}

Table 3. Summary of features most frequently commented on in Task 1 (Identify).

The most noticeable features in the American extract seem to be, in descending order, comments about the pronunciation of vowels in general, followed by comments about /t/, GOAT and /r/, for example:

- drOps pronounced drAps

- He pronounces the 'o' like ' $u$ ren j' instead of 'O renj' 
- the vowels are more open

- the T is harder/is dentalised/is stressing/sounds like ' $\mathrm{d}$ '

- he says 'tost' not 'toast'/says it like /toust/ instead of /təust/

- toasts: the sound "oa" is very opened

- the $\mathrm{R}$ is rolled/pronounced stronger

- the R of the word MURDER is rhotic

Degree of enunciation, speech rate and intonation are the next most frequently commented upon features, although none of the $2^{\text {nd }}$ year students commented on the speaker's enunciation. Comments about speech rate refer to how slowly the speaker in the recorded extract spoke.

The bulk of students' comments about the British extract concerned realisations of $/ \mathrm{t} /$ (almost twice as many) and $/ \mathrm{r} /$, followed by remarks about vowels:

- The $\mathrm{T}$ is very emphasised/ is pronounced as a T

- She pronounces the T in 'cities' whereas Americans unstress the middle

- $\mathrm{R}$ is less audible than the American one, which is harder

- her Rs are softer/are smoother

- 'model' is pronounced /mb/ more British than /ma:/ in American.

- $\quad$ all the vowels aren't stressed

- 'she uses the 'o' in a proper phonetic way, compared to the American in the first question, where he pronounced it with a ' $u$ '",

It is unclear which aspects of intonation one student was referring to by saying the British speaker has a posh intonation. The student wrote the term intonation, but may also have been noticing a mixture of articulatory setting or voice quality, or simply expressing sociolinguistic or cultural stereotypes. Speech rate was also commented on but less so than for the American extract.

Finally, in Task 1 the outliers fell into six categories:

- Syllables (3): (the American) doesn't insist a lot on syllables; doesn't stress syllables a lot; accentuates the first syllable of words

- $\quad$ Rhythm (2): (the British) tend to end their sentences with a rather up rhythmic melody; Brits mark rhythm with consonant sounds

- Word Endings (2): word endings; terminations ${ }^{4}$

- Diphthongs (2): (the British speaker's) 'more' is pronounced with a diphthong; they sound different in British English

- $\quad$ Pauses (1): (the American) takes pauses

- Nasality (1): (for the British speaker) there's no sound which come from the nose

Evaluative comments from Task 1 were recategorized, to reveal six key themes: Energy, Length, Speech rate, Shape, Ease of understanding and Similarities with French (Table 4):

\footnotetext{
${ }^{4}$ This is probably an anglicized spelling of the French word terminaison referring to word endings.
} 


\begin{tabular}{|c|c|c|c|c|}
\hline \multirow{2}{*}{$\begin{array}{c}\begin{array}{c}\text { Theme of evaluative } \\
\text { comments }\end{array} \\
\text { Extract } \\
\end{array}$} & \multicolumn{2}{|c|}{$\begin{array}{c}\mathbf{n}^{\circ} \text { of } 1^{\text {st }} \text { year } \\
\text { students' } \\
\text { comments } \\
(n=30)\end{array}$} & \multicolumn{2}{|c|}{$\begin{array}{c}\mathrm{n}^{\circ} \text { of } 2^{\text {nd }} \text { year } \\
\text { students } \\
\text { comments } \\
(n=27)\end{array}$} \\
\hline & Amer & Brit & Amer & Brit \\
\hline Energy & 13 & 14 & 5 & 4 \\
\hline Length & 8 & 3 & 1 & 0 \\
\hline Speech rate & 2 & 3 & 2 & 2 \\
\hline Shape & 1 & 2 & 3 & 1 \\
\hline Ease of understanding & 2 & 1 & 0 & 1 \\
\hline Similarities w French & 0 & 0 & 1 & 0 \\
\hline Totals: & 26 & 23 & 12 & 8 \\
\hline
\end{tabular}

Table 4. Summary of results for Task 1 (Identify) recategorized as evaluative themes.

Energy encompasses comments using words such as strong, hard, insist, emphasis, noticeable, stress, pronounce more, accentuating. Length includes comments with the adjectives longer/shorter but also two comments made by first-year students regarding the American speaker: eats words and swallows consonants. However, it is unclear whether the students were referring to the shorter duration of unstressed syllables, to prefortis clipping, or perhaps elision. Speech rate includes comments with words such as slow, fast whereas Shape covers comments about sounding round, open, flat, i.e. the British speaker sounds less flat and her words are more round.

Overall, 69 evaluative comments were made, with proportionately more from the first-year students: 49 comments for 30 students vs. 20 comments for 27 students. The most common themes in decreasing order were: Energy (36), Length (12), Speech rate (9), Shape (7), Ease of understanding (4), and one comparative comment about French. Energy expenditure seems to be a salient feature, especially for first-year students. Saying that the British speaker's English sounded softer was also included in this theme. Comments about length concern both the American speaker (he makes some syllables last) and the British one (short on the consonants; the $O$ of model sounds longer). In relation to Speech rate, one first-year student found the British speaker had quicker vowels. The theme Ease of understanding groups together comments about the impact on listeners of the speaker's English, for example Americans tend to mince words so we must listen closely to understand and this speaker in particular was more difficult to understand. The only comparison with French comes from a second-year student:

Also the way the word "before" is pronounced, particularly the 'e' is a clue to know which accent it is: with an American accent, the ' $\mathrm{e}$ ' in "before" is pronounced just like a French ' $\mathrm{e}$ ', and this is how it is pronounced here in the recording.

\subsection{Task 2: How to sound more ...}

The top four features commented on in Task 2 (What do you do to sound more...?) are shown in Table 5, in descending order by frequency of occurrence: 


\begin{tabular}{|l|c|l|c|}
\hline \multicolumn{2}{|c|}{ American target accent } & \multicolumn{2}{c|}{ British target accent } \\
\hline $\begin{array}{c}\text { Features commented } \\
\text { on ... }\end{array}$ & $\begin{array}{c}\text { Total } \mathbf{n}^{\circ} \\
\text { of } \\
\text { comments } \\
(\mathbf{n}=\mathbf{6 0})\end{array}$ & $\begin{array}{c}\text { Features commented } \\
\text { on ... }\end{array}$ & $\begin{array}{c}\text { Total } \mathbf{n}^{\circ} \\
\text { of } \\
\text { comments } \\
(\mathbf{n}=\mathbf{6 0})\end{array}$ \\
\hline$/ \mathrm{r} / \mathrm{46}$ & Vowels & 40 \\
\hline$/ \mathrm{t} / \mathrm{V}$ & 33 & $/ \mathrm{r} /$ & 37 \\
\hline Vowels & 20 & $/ \mathrm{t} /$ & 22 \\
\hline Speech rate & 12 & Speech rate & 9 \\
\hline
\end{tabular}

Table 5. Summary of features most frequently commented on in Task 2 (How to sound).

In order to sound more American, realisations of $/ \mathrm{r} /$ seem to be the most salient feature (46), followed by /t/ (33) and then vowels (20). However, in order to sound British, it is vowels which are the most frequently commented on feature (40), followed closely by $/ \mathrm{r} /$ (37) whereas $/ \mathrm{t} /$ is not commented on as frequently for this accent (22). Vowel-related comments were quite varied, for example unstress most of the vowels, make vowels echo in the mouth, kind of internalize the vowels, a $\rightarrow / e I /$, a lot of / $/$ / and the $A$ resembles an $O$. Appreciations of speed are also variable, especially for a British accent. The four comments from second-year students advise one to speak more slowly, whereas three of the five first-year student comments recommend faster speech. To sound more American, the students are closer to agreeing that one needs to speak faster. Consonants seem to contribute more to sounding American than to sounding British. In this Task, three comments were outliers: try to speak louder, use contractions and another one about gestures think of an American I know and speak \& gesture like them.

In Task 2 students were asked to explain what they do to sound more American or British. As in Task 1, some students simply provided bullet-point lists of features. However, 25 of the 33 first-year students made evaluative comments and all but one of the 23 second-year students did so. The most prescriptive example came from a secondyear student: I'll never - never!- adopt the 'creaky voice'!. All evaluative comments from Task 2 were recategorized, to reveal key themes of which the seven most common are presented in Table 6:

\begin{tabular}{|l|c|c|c|c|}
\hline $\begin{array}{c}\text { Theme of evaluative } \\
\text { comments }\end{array}$ & \multicolumn{2}{|c|}{$\begin{array}{c}\mathbf{n}^{\circ} \text { of } \mathbf{1}^{\text {st }} \text { year } \\
\text { students' } \\
\text { comments } \\
(\mathbf{n}=\mathbf{3 3 )}\end{array}$} & $\begin{array}{c}\mathbf{n}^{\circ} \text { of } \mathbf{2}^{\text {nd }} \text { year } \\
\text { students } \\
\text { comments } \\
\text { (n=27) }\end{array}$ \\
\hline \multicolumn{1}{|c|}{ To sound more... } & Amer & Brit & Amer & Brit \\
\hline Enunciation/Clarity & 13 & 9 & 9 & 12 \\
\hline Attitude & 8 & 14 & 6 & 10 \\
\hline Physicality & 16 & 7 & 8 & 2 \\
\hline Energy/Length & 6 & 8 & 4 & 6 \\
\hline Speech rate & 7 & 4 & 7 & 5 \\
\hline Diphthongs & 2 & 3 & 0 & 2 \\
\hline
\end{tabular}




\begin{tabular}{|l|c|c|c|c|}
\hline $\begin{array}{c}\text { Theme of evaluative } \\
\text { comments }\end{array}$ & \multicolumn{2}{|c|}{$\begin{array}{c}\mathbf{n}^{\circ} \text { of } \mathbf{1}^{\text {st }} \text { year } \\
\text { students } \\
\text { comments } \\
(\mathbf{n}=\mathbf{3 3})\end{array}$} & $\begin{array}{c}\mathbf{n}^{\circ} \text { of } \mathbf{2}^{\text {nd }} \text { year } \\
\text { students } \\
\text { comments } \\
(\mathbf{n}=\mathbf{2 7})\end{array}$ \\
\hline To sound more... & Amer & Brit & Amer & Brit \\
\hline Music & 1 & 3 & 0 & 2 \\
\hline Totals: & 53 & 48 & 34 & 39 \\
\hline
\end{tabular}

Table 6. Summary of results for Task 2 (How to sound) recategorized as evaluative themes.

The themes in Task 2 are labelled with terms more widely used in the phonetics/phonology literature (Speech rate, Diphthongs), as well as less obvious impressionistic terms (Physicality, Music). Concerning Enunciation/Clarity, this theme includes obvious comments such as The sounds are quite distinct, Sounds are more clear and advice to articulate less/more/a lot. Comments about eat and swallow are also included in the Enunciation/Clarity theme: swallow some consonants (like in potaTo, tomaTo), the T is swallowed and kind of 'eat' words. Physicality includes remarks about posture, props and articulators, especially features of articulatory setting (Honikman, 1964). The scope of Energy/Length is best illustrated by the verbs chosen: lengthen or elongate (words, vowels, sounds), accentuate (words, syllables, letters), stress (words, most of the vowels). Other advice says to soften consonants esp. $R$ or push on the $R$ sound. The advice whereby the vowels are 'vomited' a bit (se vomissent) was also included, as different to comments with eat or swallow because of the necessarily violent energetic explosion which is involved. Finally, the theme Music includes comments about intonation, tone and pitch.

Overall, 174 evaluative comments were made. Proportionately almost the same amount was made by each group of students: 101 comments for 33 first-years vs. 73 comments for 27 second-years. The most frequent comments were about Enunciation/Clarity (43), Attitude (38) and Physicality (33), followed by Energy/Length (24) and Speech rate (23). Diphthongs were mentioned in seven comments and six comments were catagorized as Music. First-year students made proportionately more comments about Physicality for both accents.

Comparing the two accents, Attitude was more commonly mentioned in relation to sounding British (24 vs. 14 for American) whereas Physicality was more commonly linked to sounding American (24 vs. 9 for British). The number of comments about Enunciation/Clarity was almost the same for sounding more American (22) and British (21). This is also the theme where most comments about letters were placed, for example: All the letters are pronounced, Pronounce $R$ more/less. Eleven of the 12 second-year students' comments recommend one to articulate more to sound British and eight out of the nine first-year students' comments concurred. Of the 27 second-year students, only nine commented on how to sound more American but two-thirds recommend one to articulate less. Similarly, nine of the 13 comments from first-year students advise one to articulate less.

Regarding the category of Speech rate, for second-year students one needs to speak faster to sound more American (five out of seven comments), with take time to 
pronounce the vowels assumed to indicate a slower speech rate. All except one first-year comment (six out of seven) mentioned that an American accent requires faster speech.

Attitudinal comments on the whole do not use positively connotated words to describe how to sound British. While try to be royal, imitate Emma Watson/the Queen, or even posh it up! are not necessarily negative, the following are:

- $\quad$ Speak like a pretentious person/take on a pretentious air

- Sound more snobbish/more haughty

- Show off a bit

- $\quad$ Need to sound more superior and pompous

- $\quad$ Get myself into a more uptight state of mind

To sound American, on the other hand, take yourself less seriously, be 'casual', more relaxed, more detached, make it more 'cool' or adapt a kind of neighbourhood behaviour/modern one.

The Physicality theme includes a variety of remarks, such as:

- Speak with the back of your throat

- $\quad$ Need a deeper voice, need to sound 'creaky'

- Make $\mathrm{OH}$ with a ping-pong ball in your mouth

- Speak like you have a potato in your mouth/speak into your 'beard/chin'

- I stand up straight because I feel like I need more air in order to pronounce things more correctly

- Do more 'round' sounds

- Americans do not move their lips as much as Brits

The students definitely show awareness of physical differences, regardless of their comments' linguistic accuracy or feasibility.

Concerning diphthongs, seven students wrote that a British accent has more diphthongs than an American one. It is odd that more students did not mention diphthongs, given that the GOAT diphthong is the most commonly dealt with segmental feature (along with /i:/) in secondary school textbooks in France (Henderson \& Jarosz, 2014) and that it is realised differently in these two accents. Similarly, only six out of sixty students noted anything about intonation, tone or pitch (Music) as features to modify in order to imitate one or the other accent, i.e. use lower tone and try to do the level sound like the Queen.

It is interesting to note that analogies, metaphors and similes are almost entirely absent from the students' comments. One second-year student produced the only two true analogies: fruit salad/smoothie and dentelle, the latter to describe British English.

\subsection{Discussion Comparing Task 1 and Task 2}

To briefly summarize the key results from both Tasks, Table 7 shows the results for features most frequently commented on, in descending order, with results for the two accents combined: 


\begin{tabular}{|c|c|c|c|}
\hline \multicolumn{2}{|c|}{ Task 1 $(\mathrm{n}=57)$} & \multicolumn{2}{c|}{ Task 2 $(\mathrm{n}=60)$} \\
\hline Feature & $\boldsymbol{n}^{\circ}$ of comments & Feature & $\boldsymbol{n}^{\circ}$ of comments \\
\hline$/ \mathrm{t} /$ & 53 & $/ \mathrm{r} /$ & 83 \\
\hline$/ \mathrm{r} /$ & 36 & Vowels & 60 \\
\hline Vowels & 31 & $/ \mathrm{t} /$ & 55 \\
\hline Total & 120 & Total & 198 \\
\hline
\end{tabular}

Table 7. Most common features referred to in Task 1 (Identify) and Task 2 (How to sound).

For these three features, fewer comments were made in Task 1 (Identify) than in Task 2 (How to sound), so the latter prompt seems more productive. The learners might also have said more because they had had two more months of instruction since doing Task 1. Whereas comments about realisations of /t/ are the most frequent in Task 1 , in Task 2 they are the third most common, but in proportionately similar amounts. It is worth noting that spelling-pronunciation relationships were mentioned explicitly in Task 1 (i.e. the way the word 'before' is pronounced, particularly the ' $e$ ' is a clue to know which accent it is) but in Task 2 these can only be inferred from comments such as each letter is pronounced or use every letter in words.

Contrastive analysis predicts that French learners of English would be expected to comment on vowels, diphthongs, realisations of $/ \mathrm{t} /, / \mathrm{r} /, / 1 /$ and $/ \mathrm{P} /$, and perhaps voice quality. Overall, in the two data collections of this study, realisations of $/ \mathrm{t} / \mathrm{h} / \mathrm{r} /$, and vowels were the most frequently commented upon. No one ever mentioned glottal stops or velarized $/ 1 /$. It could be that these are not particularly salient features for these students or perhaps they did not have the words to refer to them. Very few comments involved voice quality. In Task 1 nasality was noticed by a first-year student: there's no sound which come from the nose. In Task 2, three participants commented on two qualities of an American accent: one needs a deeper voice and one needs to sound creaky or use a kind of creaky voice.

The effect of the prompts was obvious in the recategorization of evaluative comments, with three categories emerging uniquely for Task 1 replies (Shape, Ease of understanding, Similarities with French), and three others solely for Task 2 (Attitude, Physicality, Enunciation/Clarity, Music). Comments about Energy, Length and Speech rate were found in both datasets. Task 1 elicited far more comments about Energy and Length (48/69) than in Task 2 (24/173). Moreover, the nature of the question in Task 2 (What do you do to sound more ...?) might explain the appearance of attitudinal comments (39). In Task 2, attitude was more commonly mentioned - and with negative connotations - about how to sound British whereas advice about Physicality (articulators, posture or props) was more commonly mentioned in relation to sounding more American.

It seems important that in both tasks the participants wrote about a greater expenditure of energy, even if they think that ' $R$ ' is more accentuated. If they are noticing greater levels of energy and differences of length, perhaps their "stress deafness" (Frost, 2011) is not inevitable. While it is difficult to determine the acoustic correlates of stress, according to Lehiste "For English, the order of importance (in the perception of stress) appears to be the following: Duration is more important than 
intensity" (Lehiste, 1976, p. 235). The perception of greater energy and/or length could be exploited in the pedagogical treatment of stress, whether one tends toward an articulatory approach or a listen-and-repeat approach.

\section{Conclusion and Future Work}

This study has provided some thought-provoking results and it obviously calls for measurement of the impact of awareness-raising exercises on learners' perception and production. Measurement could be done by assessing their oral productions, before and after such an exercise.

There are three main methodological limitations of this study: the recordings were not the same discourse type and more students could have been involved. Moreover, only one person categorized the comments but this was done twice with a three-month break in between; other colleagues were consulted when a comment was classified differently after the break. These shortcomings could be remedied in replication studies, which would be easy to carry out. For example, this study only required students to write for 10-15 minutes. While the analysis took much longer, the categories generated by their answers could provide useful insight for teachers who want to better understand their own students' implicit concepts. Written comments could then be recycled in the classroom, providing content for awareness-raising exercises, such as Dörnyei promotes:

Language teaching programmes need to include a featured awareness-raising component, highlighting the importance of 'meta-cognitive control strategies', which is part of selfmotivation. Of course, as in so many other areas, the secret lies in the details, that is, in finding the right balance of explicit-implicit treatment and in providing the right type of form-focused (i.e. metalinguistic) and motivational (i.e. metacognitive) training. (2009, 173-74)

The participants' comments were not always linguistically accurate, for example saying that American English has more vowels that are rounded. However, their degree of accuracy was not important in this study. The key insight here is that lip rounding is a salient feature for some of them and, therefore, should be included in feedback. Such comments, though inaccurate, are an excellent starting point for a teacher. Learners can focus attention on the feature and then move towards a more accurate explicit concept and, in turn, an implicit one that affects production.

It would also be useful to have a longitudinal perspective, to see whether or not certain features become more or less salient over time; one issue would be how to elicit such comments from the same students over subsequent semesters or years, without suffering a test-effect. Furthermore, cross-linguistic comparisons would show whether learners from different mother tongues, i.e. tonal or more syllable-timed languages, find different features salient. Initial, as yet unpublished results from Spanish students support this hypothesis.

It was hoped that these students' linguistically naive remarks would include conceptual metaphors (Lakoff \& Johnson, 1980), similes, personifications, etc. However, only two true analogies were found: fruit salad/smoothie and dentelle. 
Likewise, only one student compared English with French; arguably awareness of their native language should be heightened and exploited.

The goal of pronunciation instruction according to Fraser should be to "help learners develop concepts that make these aspects of speech as obvious to the learner as they are to native speakers" (2011, p. 130). As part of a holistic programme of EFL pronunciation instruction (Szpyra-Kozlowska, 2014), salient features could be discussed and/or elsewise worked on explicitly. The metalanguage with which teachers address these subjects should be carefully chosen and could be based on students' written comments. Simple tasks could provide the raw material for awareness-raising activities, and the former could be verbal, as in this study, or aural, visual, gestural. Once teachers have identified features which their learners find salient, numerous suggestions for classroom activities can be found in articles, books, and Web-based resources. One such free resource is Huckvale's RTPitch software (2009), which merits greater use. Teachers might also want to consider non-imitative approaches such as Silent Way techniques, for example as updated by Young and Messum (2011). If these same teachers then carried out action research, valuable contributions could be made to research into the effectiveness of pronunciation instruction (i.e. Thomson \& Derwing, 2014; Lee, Jang, \& Plonsky, 2015).

All these ideas can be seen as open windows which provide a broader view of pronunciation teaching and learning, changing our focus from the language's features to learners' conceptions of those features. This could be a soft way to keep just the right amount of fruit chunks in their smoothies. 


\section{References}

Bloch, B., \& Trager, G. (1942). Outline of Linguistic Analysis. Baltimore: Linguistic Society of America.

Boughton, Z. (2006). When perception isn't reality: Accent identification and perceptual dialectology in French. Journal of French Language Studies 16(3), 277-304. DOI: http://dx.doi.org/10.1017/S0959269506002535

Bruner, J., Goodnow, J. J., \& Austin, G. A. (1967). A Study of Thinking. New York: Science Editions.

Celce-Murcia, M., Brinton, D. M., Goodwin, J. M., \& Griner, B. (2010). Teaching Pronunciation (2nd ed.). Cambridge: Cambridge University Press.

Couper, G. (2011). What makes pronunciation teaching work? Testing for the effect of two variables: socially constructed metalanguage and critical listening. Language Awareness 20(3), 159-182.

Couper, G. (2006). The short and long-term effects of pronunciation instruction. Prospect 21(1), 46-66.

DeKeyser, R. M., \& Juffs, A. (2005). Cogntive considerations in L2 learning. In E. Hinkel (Ed.), Handbook of Research in Second Language Teaching and Learning (pp. 437-454). Mahwah, NJ: Lawrence Erlbaum

Dörnyei, Z. (2009). The Psychology of Second Language Acquisition. Oxford: Oxford University Press.

Ellis, N. C. (2006). Selective attention and transfer phenomena in L2 acquisition: Contingency, cue competition, salience, interference, overshadowing, blocking, and perceptual learning. Applied Linguistics 27(2), 164-194.

DOI: 10.1093/applin/aml015

Fraser, H. (2011). Speaking of speech: Developing metalanguage for effective communication about pronunciation between English language teachers and learners. In A. Henderson (Ed.), Proceedings of the International Conference on English Pronunciation: Issues \& Practices (pp. 119-138). Université de Savoie, June 2009, Chambéry, France. Available at http://helenfraser.com.au/hf/wp-content/uploads/HFEPIP.pdf.

Fraser, H. (2006). Phonological concepts and concept formation: Metatheory, theory and application. International Journal of English Studies, Monograph on Cognitive Phonology 6(2), 55-75.

Frost, D. (2011). Stress and cues to relative prominence in English and French: A perceptual study. Journal of the International Phonetic Association 41(1), 67-84. DOI: http://dx.doi.org/10.1017/S0025100310000253

Henderson, A., \& Jarosz, A. (2014). Desperately seeking a communicative approach: English pronunciation in a sample of French and Polish secondary school textbooks. Research in Language 12(3), 261-277. DOI: 10.2478/rela-2014-0015

Honikman, B. (1964). Articulatory settings. In D. Abercrombie et al. (Eds.), In Honour of Daniel Jones (pp. 73-84). London: Longman.

Huckvale, M. (2009). RTPitch (computer program). Available at: http://www.phon.ucl. ac.uk/resource/sfs/rtpitch/ 
Hume, E., \& Johnson, K. (2001). A model for the interplay of speech perception and phonology. In E. Hume \& K. Johnson (Eds.), The Role of Speech Perception in Phonology (pp 3-26). New York: Academic Press.

Kirkova-Naskova, A., Tergujeff, E., Frost, D., Henderson, A., Kautzsch, A., Levey, D., Waniek-Klimczak, E. (2013). Teachers' views on their professional training and assessment practices: Selected results from the English Pronunciation Teaching in Europe survey. In J. Levis \& K. LeVelle (Eds.), Proceedings of the 4th Pronunciation in Second Language Learning and Teaching Conference (pp. 29-42). Aug. 2012. Ames, IA: Iowa State University.

Lakoff, G., \& Johnson, M. (1980). Metaphors We Live By. Chicago: University of Chicago Press.

Leather, J. (1999). Second language speech research: An introduction. In J. Leather (Ed.), Phonological Issues in Language Learning (pp 1-56). Oxford: Blackwell.

Lee, J., Jang, J., \& Plonsky, L. (2015). The effectiveness of second language pronunciation instruction: A meta-analysis. Applied Linguistics 36(3), 345-366. DOI: 10.1093/applin/amu040

Lehiste, I. (1976). Suprasegmental Features of Speech. In N. Lass (Ed.), Contemporary Issues in Experimental Phonetics: Perspectives in neurolinguistics and psycholinguistics (pp. 225-242). New York: Academic Press.

Preston, D. (2011). Methods in (applied) folk linguistics: Getting into the minds of the folk. AILA Review 24(3), 15-39. DOI: 10.1075/aila.24.02pre

Preston, D. (1999). Introduction. Handbook of Perceptual Dialectology. In D. Preston (Ed.), (pp xxiii-xl ). Amsterdam: John Benjamins.

Rasier, L., \& Hiligsmann, P. (2007). Prosodic transfer from L1 to L2. Theoretical and methodological issues. Nouveaux cahiers de linguistique française (28), 41-66.

Saussure, F. (1916/2013). Course in General Linguistics. P. Meisel \& H. Saussy (Eds.), (W. Baskin, Trans.) (1959). Columbia University Press: New York.

Strange, W. (Ed.). (1995). Speech perception and linguistic experience: Issues in crossangauge research. Baltimore: York Press.

Szpyra-Kozlowska, J. (2014). Pronunciation in EFL Instruction: A Research-Based Approach. Bristol: Multilingual Matters.

Thomson, R., \& Derwing, T. (2014). The effectiveness of L2 pronunciation instruction: A narrative review. Applied Linguistics 2014, 1-20. DOI:10.1093/applin/amu076

Walter, C. (2001). French speakers. In M. Swan \& B. Smith, Learner English: A Teacher's Guide to Interference and Other Problems (2nd ed), (pp. 52-56). Cambridge: Cambridge University Press.

Wells, J. C. (2008). Longman Pronunciation Dictionary (3rd ed.). Harlow, Essex: Pearson-Longman.

Wells, J. C. (1982). Accents of English. Cambridge: Cambridge University Press.

Wikipedia, (2015). http://en.wikipedia.org/wiki/Virtual_learning_environment. Accessed April 27, 2015.

Wilton, A., \& Stegu, M. (2011). Bringing the 'folk' into applied linguistics. AILA Review 24(3), 1-14. DOI: 10.1075/aila.24.01wil 
Wrembel, M. (2011). Cross-modal Reinforcements in Phonetics Teaching and Learning: An Overview of Innovative Trends in Pronunciation Pedagogy. In W. S. Lee \& E. Zee (Eds.), Proceedings of the 17th International Congress of Phonetic Sciences (pp 104-107). 17-21 August 2011. Hong Kong. CD-ROM. Hong Kong: City University of Hong Kong.

Wrembel, M. (2005). Metacompetence-oriented model of phonological acquisition: implications for the teaching and learning of second language pronunciation. In Proceedings of the Phonetics Teaching and Learning Conference PTLC2005 (pp 1-4) (CD edition). London: UCL.

Young, R., \& Messum, P. (2011). How We Learn and How We Should Be Taught. London: Duo Flumina. 


\section{Appendix: Texts of extracts}

American extract, Jerry Seinfeld (15 seconds): It was the sixties and we had toast. We had orange juice that was frozen years in advance that you had to hack away at with a knife to get a couple of drops. And it felt like you were committing a murder before you got on your schoolbus.

British extract, BBC FastTrack presenter (11 seconds): As more and more cities ponder how to cater for the twelve billion of us predicted to be flying in twenty years time, Greg Lindsay remains convinced that the "aerotropolis" is the model for the future. 